\title{
Fine Scale Precipitates in Al-Mg-Zn Alloys after Various Aging Temperatures
}

\author{
Nasser Afify*, Abdel-Fattah Gaber, Ghada Abbady \\ Physics Department, Faculty of Science, Assiut University, Assiut, Egypt. \\ Email: afify@aun.edu.eg \\ Received March $5^{\text {th }}, 2011$; revised April 13 $3^{\text {th }}, 2011$; accepted April $27^{\text {th }}, 2011$.

\begin{abstract}
This article deals with investigation of fine-scale precipitation in Al-Mg-Zn alloys with compositions of $\mathrm{Al}-2$ at\% $\mathrm{Mg}$ $x$ at $\% \mathrm{Zn},(x=1.8,2$ and 4.2$)$. The precipitates morphology was examined by scanning electron microscope (SEM) and correlated with the microhardness (HV) and differential scanning calorimetry (DSC) of the specimens. The precipitates are characterized as $\eta^{\prime}\left(\mathrm{MgZn}_{2}\right)$ and $\eta\left(\mathrm{MgZn}_{2}\right)$ phases of hexagonal structure of the same composition with a slight difference in lattice parameters. In addition, T-phase pf composition $\left(\mathrm{Mg}_{32}(\mathrm{Al}, \mathrm{Zn})_{49}\right)$ having a cubic crystal structure. Owing to the determined activation energies of the precipitates, the kinetics associated with their nucleation and growth can be characterized. The thermal energy acquired during aging leads to the agglomeration of precipitates to or larger particle sizes.
\end{abstract}

Keywords: Al-Mg-Zn Alloys, Coherent Precipitates, Aging, Microhardness, Scanning Electron Microscopy, Precipitation Kinetics

\section{Introduction}

Aluminum magnesium alloys are preferred, particularly for automotive vehicle manufactures who aim to produce lightweight vehicles. Reducing the weight and thus increasing the fuel efficiency of vehicles is becoming an important objective for the automotive industry as governments introduce regulations for exhaust emission [1].

The addition of zinc to the Al-Mg alloy system reduces the solid solubility of aluminum in magnesium, increasing the amount of precipitate phase formed upon aging and thus causing a moderate increase in strength $[1,2]$. However, the phenomena of precipitation and the mechanisms which govern them remain subject of intensive research concerning the number and the nature of the phases that appear in these alloys as well as the heat and/or thermo mechanical treatment which are essential for obtaining the necessary mechanical properties. The phenomena of transformation of phases in these alloys are most complex among all alloys based on aluminum [3].

Aging processes in most aluminum alloys are complex and the decomposition of saturated solid solutions obtained by quenching takes place in several stages. Typically, coherent Guinier-Preston (G.P.) zones and semi- coherent intermediate precipitates precede the formation of the incoherent equilibrium precipitates [4,5]. The intermediate precipitates in the various alloys have generally been considered to have the same compositions as the respective equilibrium precipitates, although the crystal structures differ because the former maintain partial coherency with the parent lattice.

The modification of precipitates involves the following four transformation reactions [6]:

1) direct formation of coherent precipitates from the solid solution; e.g. G.P. zones;

2) growth or transformation of coherent precipitates, G.P. zones to other coherent forms; $\eta^{\prime}\left(\mathrm{MgZn}_{2}\right)$ and $T$ $\mathrm{Mg}_{32}(\mathrm{Al}, \mathrm{Zn})_{49}$ or $\left(\mathrm{Al}_{2} \mathrm{Mg}_{3} \mathrm{Zn}_{3}\right)$;

3) dissolution of precipitates;

4) formation of incoherent precipitates $\eta$ and $T$ from the solid solution at high temperature.

Other works reported that the precipitation sequence in Al-Mg-Zn alloys is:

$\alpha$-Supersaturated solid solution ( $\alpha$-sss) $\rightarrow$ Guinier-Preston zones (GP zones) $\rightarrow$ metastable phase $\eta^{\prime}$ (Hex) $\rightarrow$ equilibrium phase $\eta\left(\mathrm{MgZn}_{2}\right)(\mathrm{Hex})[7,8]$.

\section{Experimental Procedures}

In order to study the decomposition and precipitation in 
supersaturated Al-Mg-Zn alloys, three specimens of Al 2 at $\% \mathrm{Mg}-x$ at $\% \mathrm{Zn}(x=1.8,2$ and 4.2), were prepared. The initial elements are $\mathrm{Al}(99.9 \%$ purity), $\mathrm{Mg}(99.9 \%$ purity) supplied by Aluminum Company, Naga Hammady, Egypt, and pure Zn (99.999\% purity) from Aldrich Chemical, Inc. USA. The prepared ingots were cylindrical in shape of $17 \mathrm{~mm}$ diameter.

Disc-shaped DSC samples of $5 \mathrm{~mm}$ diameter and 0.5 $\mathrm{mm}$ thickness were punched from the ingots. The specimens were solution heat treated for $1 \mathrm{~h}$ at $803 \mathrm{~K}$ followed by quenching into chilled water maintained at $\sim 273 \mathrm{~K}$. A nearly similar weight of an annealed pure Al disc has been used as a reference. Nonisothermal thermograms were carried out for the as-quenched specimens using a Shcimadzu DSC thermal analyser TA-50 at various heating rates.

The dimensions of the disc-shaped specimens used for microhardness measurements (Vickers hardness HV) are about $15 \mathrm{~mm}$ diameter and $3 \mathrm{~mm}$ thickness. The specimens were polished by abrasive papers of different grades. The final polishing was achieved by using diamond paste of particle size $\sim 0.25 \mu \mathrm{m}$ on cloth. Each HV value is obtained from the average of at least ten readings distributed over the whole surface of the specimen.

For SEM, the specimens surfaces were polished and followed by etching using a solution of $1 \% \mathrm{HF}+2.5 \%$ $\mathrm{HNO}_{3}$ (by volume) in $\mathrm{H}_{2} \mathrm{O}$ (Keller etcher). The SEM examinations were performed after artificial aging for 30 min at various temperatures using JEOL-SEM 5400 LVJapan scanning electron microscope.

\section{Results and Discussion}

\subsection{Precipitation Sequence}

The studied specimens of Al- 2 at $\% \mathrm{Mg}$ alloy which contain $1.8,2$ and 4.2 at $\% \mathrm{Zn}$, were subjected to DSC technique immediately after quenching from the solid solution state $(803 \mathrm{~K})$. The specimens are non-isothermally scanned at a heating rate of $10 \mathrm{Kmin}^{-1}$ and printed in Figure 1. Figure 2 shows the variation of Vickers microhardeness, $\mathrm{HV}$, of these quenched specimens as a function of temperature.

From Figure 1 and Figure 2, five precipitation reactions are detected and explained as follows:

Peak I; ascribed to the formation of Guinier-Preston zones (G.P. zones). The abundant concentration of the quenched-in vacancies have an effective role in forming solute-vacancy complexes. The formed Zn-vacancy and $\mathrm{Mg}$-vacancy complexes may combine forming $\mathrm{Zn}-\mathrm{Mg}$ vacancy clusters. These clusters act as preferable sites for nucleation of G. P. zones, either vacancy rich G. P. zones or solute rich G. P. zones.

Peak II; represents the precipitation of $\eta^{\prime}$ intermediate

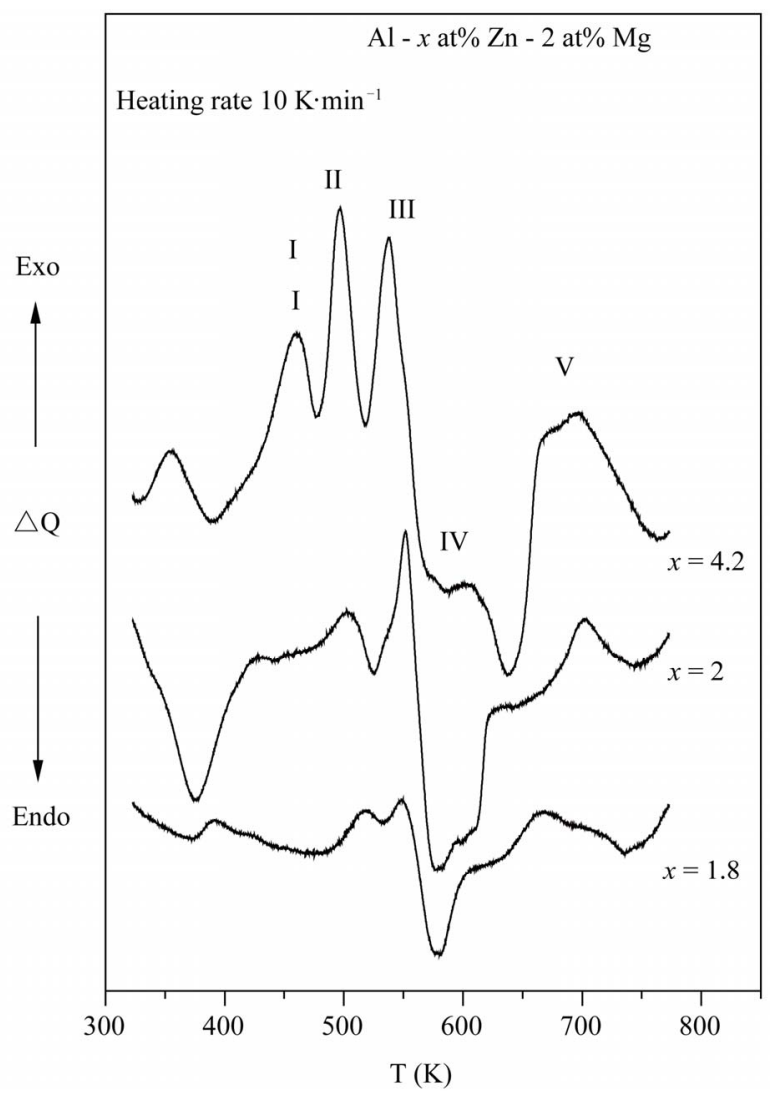

Figure 1. DSC curves of Al - 2 at $\% \mathrm{Mg}-\mathrm{x}$ at\% $\mathrm{Zn}$, at a heating rate of $10 \mathrm{~K} \cdot \mathrm{min}^{-1}$.

phase, due to the dissociation of vacancies in the zones and vacancy clusters and annealed out to grain boundaries or free surface of the specimen leaving Mg-Zn clusters. $\eta^{\prime}$ is a metastable phase $\left(\mathrm{MgZn}_{2}\right)$, characterized by a hexagonal structure with lattice parameter $a=0.50 \mathrm{~nm}, c$ $=0.87 \mathrm{~nm}[9]$.

Peak III; can be ascribed to $\eta$ stable phase $\left(\mathrm{MgZn}_{2}\right)$. Both $\eta^{\prime}$ and $\eta$ are hexagonal although the lattice parameters are slightly different lattice parameter $a=0.5225 \mathrm{~nm}$, $c=0.8568 \mathrm{~nm}$ [9].

Shoulder IV; might be ascribed to the growth and coarsening of $\eta$ precipitates $\left(\mathrm{MgZn}_{2}\right)$, noncoherent precipitates.

Peak V; can be ascribed to the nucleation and growth $\mathrm{T}^{\prime}$ precipitates $\left(\mathrm{Mg}_{32}(\mathrm{Al}, \mathrm{Zn})_{49}\right)$. The coarsening of $\mathrm{T}^{\prime}$-precipitates to form $\mathrm{T}$ the crystal structure of this phase is cubic structure of $a=1.422 \mathrm{~nm}$ noncoherent (stable precipitates) is taking place [10].

As a representative, Al- 2 at $\% \mathrm{Mg}-2$ at $\% \mathrm{Zn}$, Figure 3, shows the variation of DSC thermograms as a function of heating rate. The thermograms show that the peak temperatures shift to higher temperatures as the heating rate increases which indicate that the developed processes are thermally activated. 


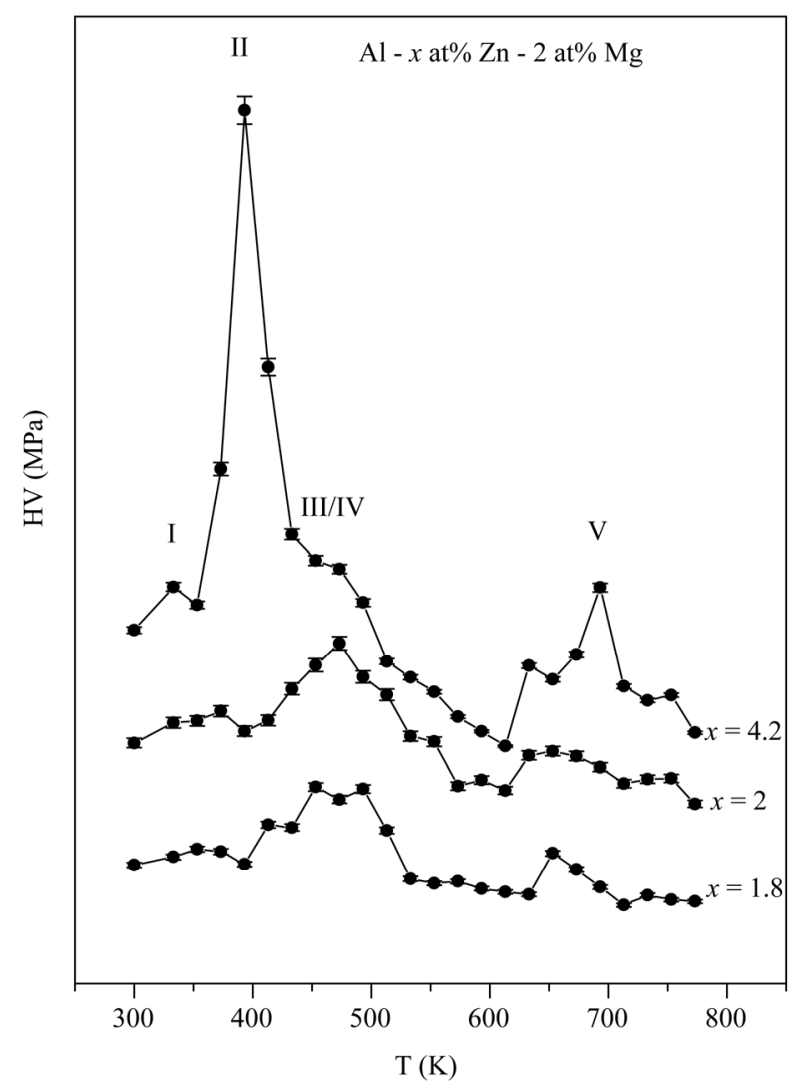

Figure 2. Behaviour of the microhardness, $\mathrm{HV}$, of the quenched $\mathrm{Al}-\boldsymbol{x}$ at $\% \mathrm{Zn}-2$ at $\% \mathrm{Mg}$, as a function of aging temperature.

The precipitation sequence can be concluded to be as follows:

Supersaturated solid solution $\rightarrow$ solute-vacancy clusters + G.P. zones $\rightarrow$ intermediate $\eta^{\prime} \rightarrow$ equilibrium $\eta \rightarrow$ $T$ - phase $\rightarrow T$ - phase

\subsection{Isothermal Aging}

The age hardening curves obtained during artificial aging for Al- 2 at $\% \mathrm{Mg}-2$ at $\% \mathrm{Zn}$ at $393 \mathrm{~K}, 498 \mathrm{~K}, 533 \mathrm{~K}$, $598 \mathrm{~K}$ and $693 \mathrm{~K}$ for representatives are shown in Figure 4. It can be observed that the age hardening behavior is influenced by the aging temperature. Increasing the aging temperature enhances the hardening behavior. In the lowest aging temperature $393 \mathrm{~K}$, the hardening precipitation peak delayed to an aging time of higher than 1000 min, above which the precipitation hardening peak begin to be reached, This result is in good agreement with L. Hadjadj et al. [3].

On increasing the aging temperature to $498 \mathrm{~K}$ a slight increase in the hardness appeared after $10 \mathrm{~min}$ of aging. The peak hardness appeared after $150 \mathrm{~min}$ due to the second hardness peak of the coherency precipitates $\eta^{\prime}$. Aging at $533 \mathrm{~K}$ the first peak hardness did not appear and

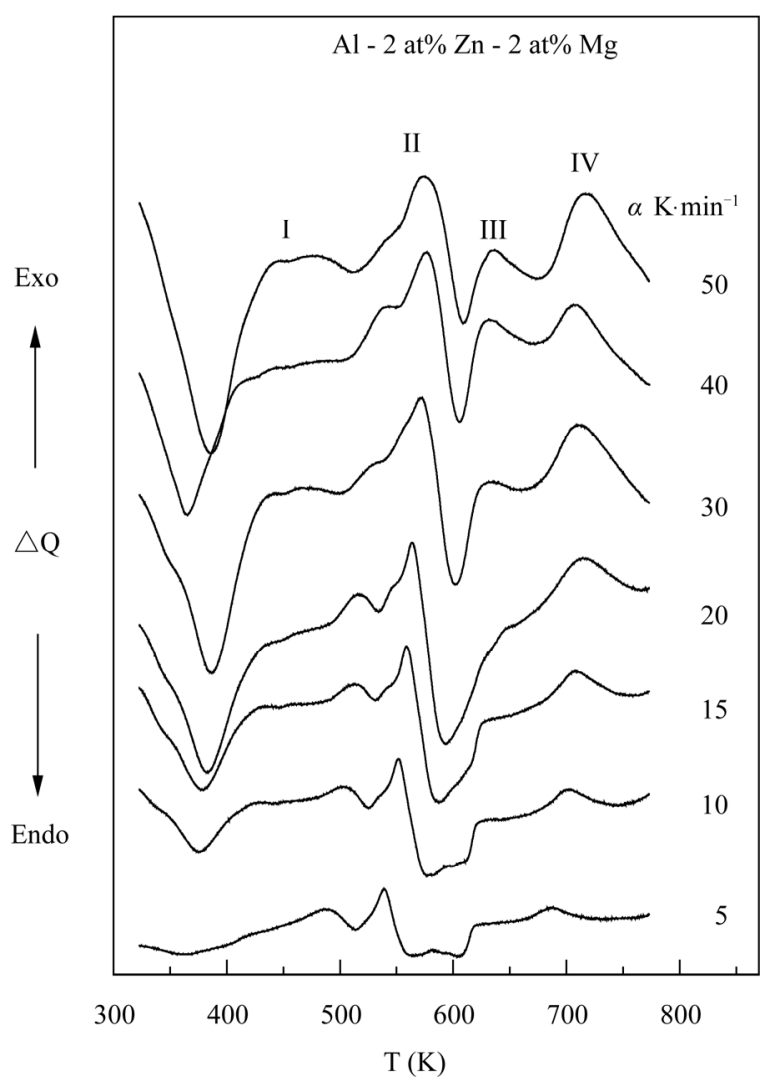

Figure 3. DSC thermograms of Al - 2 at\% $\mathrm{Mg}$ - 2 at\% $\mathrm{Zn}$ (balanced alloy), at different heating rates.

the seconded hardness peak starts at 20 min and reaches its peak after $\sim 80 \mathrm{~min}$. By increasing aging temperature to $598 \mathrm{~K}$ and $693 \mathrm{~K}$ the hardness peak shifts to the right (lower time) which means that increasing the aging temperature accelerates the nucleation of the precipitates.

The highest hardness of the specimen $>500$ MP could be achieved as a result of aging the specimen at $393 \mathrm{~K}$ for a time above $1000 \mathrm{~min}$.

The positive contribution to hardness depends on the coherency of the precipitate with the matrix, size and distribution of the precipitates and proximity of the particles $[11,12]$.

\subsection{Confirmation of Precipitation in Al- 2 at $\%$ $\mathrm{Mg}-x$ at $\% \mathrm{Zn},(x=1.8,2$ and 4.2) Alloys}

To confirm the developed processes at the DSC reaction peaks, the SEM is used for the aged specimens at each reaction peak temperature. As the specimen is aged for $30 \mathrm{~min}$ at aging temperature $473 \mathrm{~K}$, around the peak II in DSC scans ( $\eta^{\prime}$ phase) coherent phase. The SEM micrograph, Figures 5-7(a), shows the morphology of $\eta^{\prime}$ phase $\mathrm{MgZn}_{2}$ which was identified as plate-shaped particles. This result is in good agreement with T. Engdahl et al. [13]. 


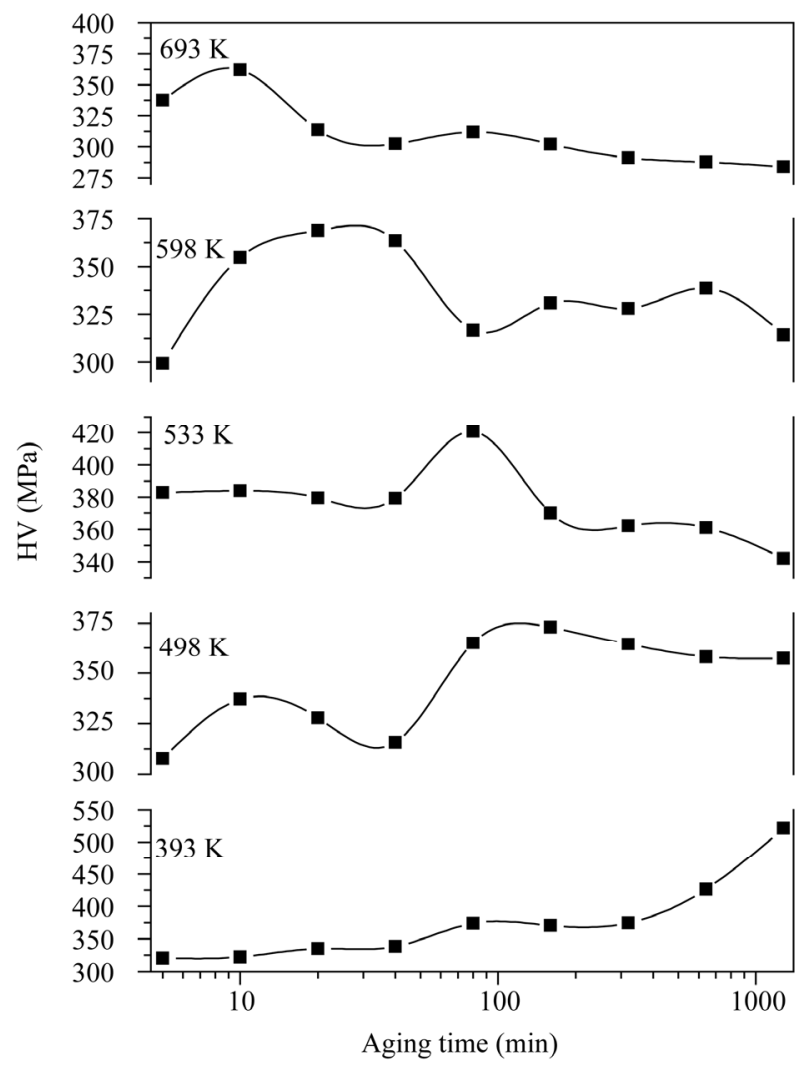

Figure 4. HV vs. aging time for $\mathrm{Al}-2$ at $\% \mathrm{Zn}-2$ at $\% \mathrm{Mg}$.
As the aging temperature is increased to the corresponding temperature of $\eta$-phase (peak III) for $30 \mathrm{~min}$ at $533 \mathrm{~K}$, the SEM micrograph is shown in Figures 5-7(a). The $\eta$-precipitates are blocky precipitates exhibit distinct faceted platelets $[4,12]$.

On raising the aging temperature to $673 \mathrm{~K}$ for $30 \mathrm{~min}$; the temperature of the peak V in the DSC scans, The SEM micrograph revealed the existence of $T$ phase $\operatorname{Mg}_{32}(\mathrm{Al}, \mathrm{Zn})_{49}$ cigar-shaped, as shown in Figures 5-7(a). The particle number density also decreased due to the coarsening of $\mathrm{T}$ particles at the expense of the number density [13] of the earlier precipitates developed at lower temperatures.

In conclusion the surface density of precipitates (number of precipitates per unite area) is decreased and the particle size increased with increasing the aging temperature.

In all studied alloys Al- 2 at $\% \mathrm{Mg}-x$ at $\% \mathrm{Zn},(x=1.8$, 2 and 4.2), the particle size of grown precipitates increased with increasing the aging temperature as shown in Figure 8. The behaviour of particle size as a function of aging temperature is found to fit exponential growth as:

$$
D=a \exp \left(\frac{T}{b}\right)+y_{0}
$$

where $a, b$ and $y_{0}$ are constants of exponential formula which are different for different alloys as shown in Table 1.

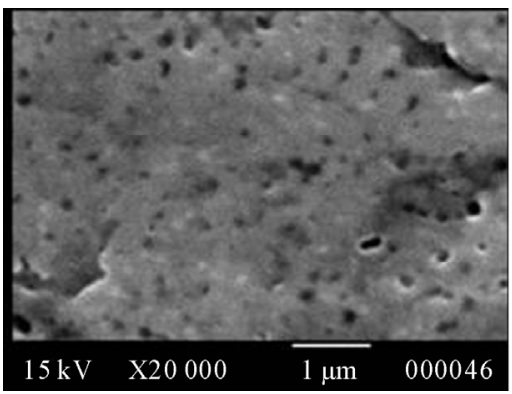

(a)

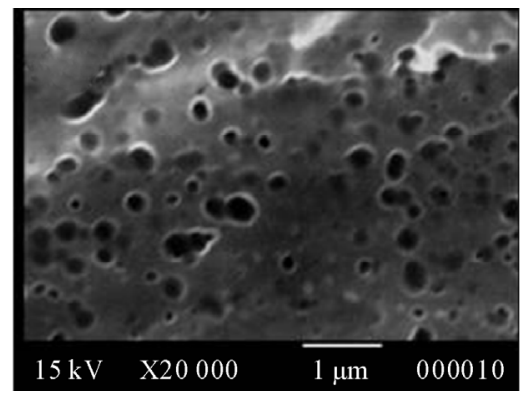

(b)

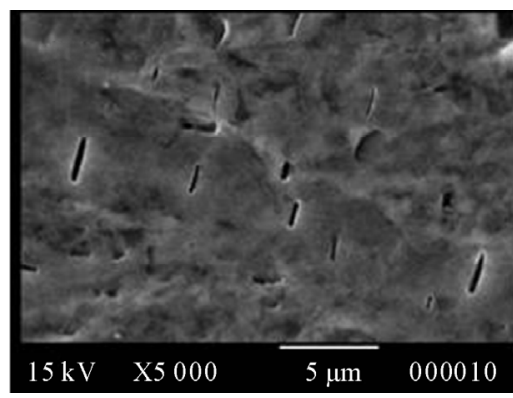

(c)

Figure 5. SEM micrograph of Al - 2 at\% Mg - 1.8 at\% $\mathrm{Zn}$ aged for $30 \mathrm{~min}$ at aging temperature. (a) $473 \mathrm{~K}$; (b) $533 \mathrm{~K}$; (c) $673 \mathrm{~K}$.

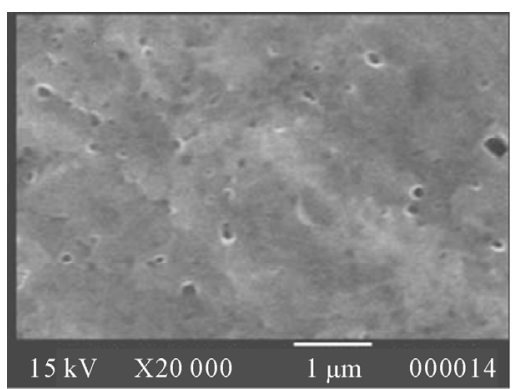

(a)

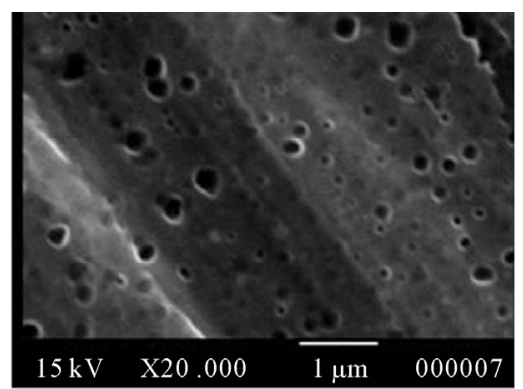

(b)

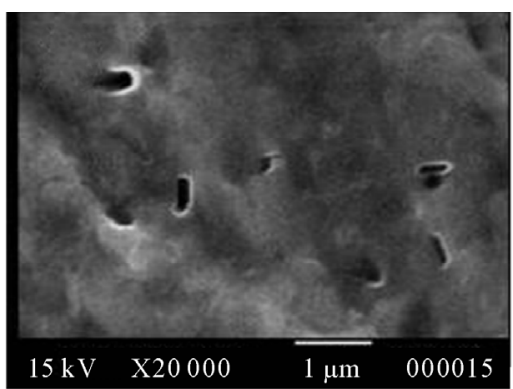

(c)

Figure 6. SEM micrograph of $\mathrm{Al}-2$ at\% $\mathrm{Mg}-2$ at\% $\mathrm{Zn}$ aged for $30 \mathrm{~min}$ at aging temperature. (a) $473 \mathrm{~K}$; (b) $533 \mathrm{~K}$; (c) $673 \mathrm{~K}$. 


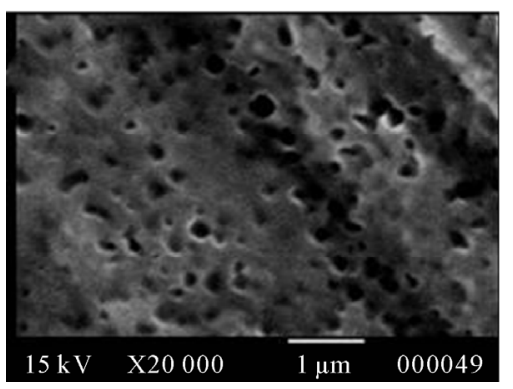

(a)

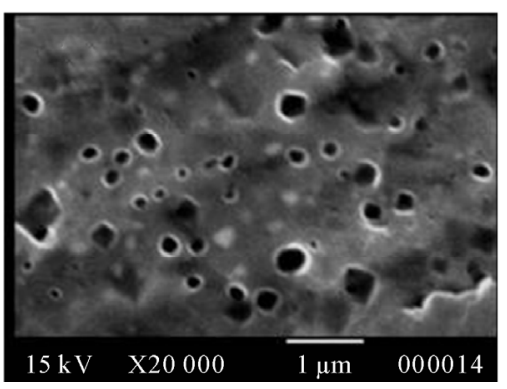

(b)

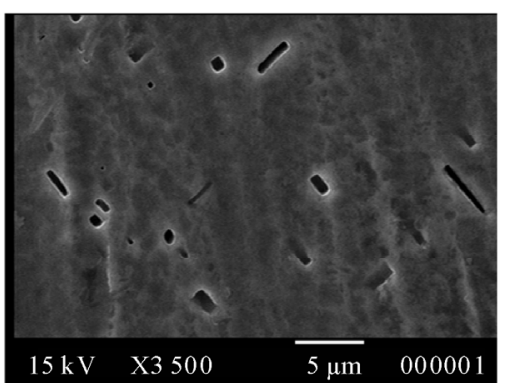

(c)

Figure 7. SEM micrograph of Al - 2 at\% $\mathrm{Mg}-4.2$ at\% $\mathrm{Zn}$ aged for $30 \mathrm{~min}$ at aging temperature. (a) $473 \mathrm{~K}$; (b) $533 \mathrm{~K}$; (c) $673 \mathrm{~K}$.

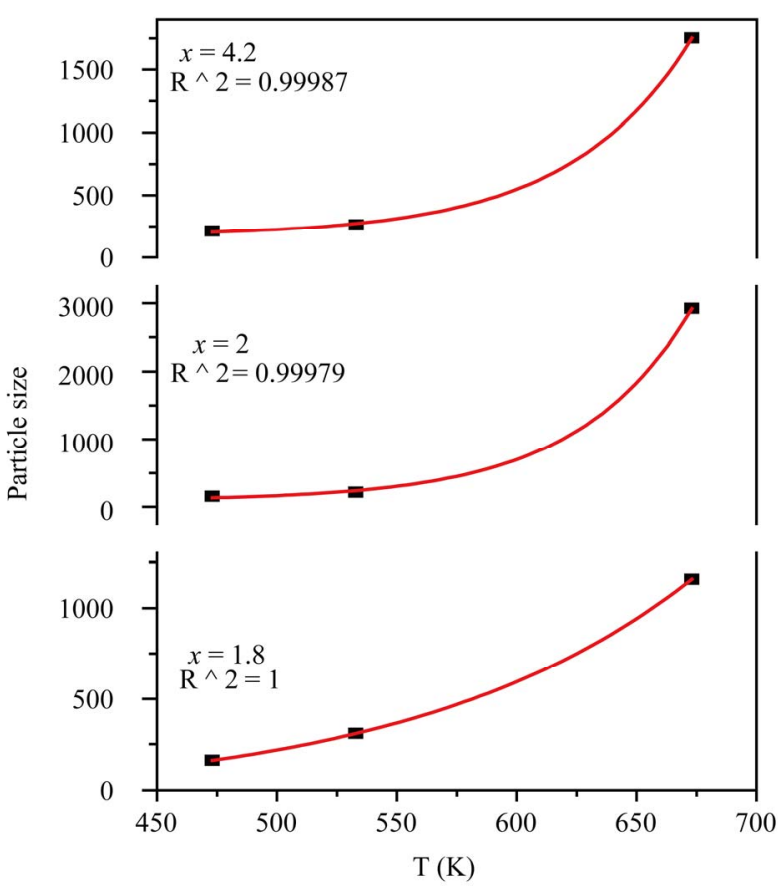

Figure 8. Particle size of precipitates vs. aging time for Al 2 at $\% \mathrm{Mg}-\boldsymbol{x}$ at\% $\mathrm{Zn}$.

Table 1. $a, b$ and $y_{0}$ constants for Al- 2 at $\%$ Mg- $x$ at\% $\mathrm{Zn}$ alloys.

\begin{tabular}{cccc}
\hline & \multicolumn{3}{c}{ constants } \\
\cline { 2 - 4 } & $a$ & $b$ & $y_{0}$ \\
\hline 1.8 & 4.10589 & 118.15519 & -64.19479 \\
2 & 0.002 & 47.52602 & 90.17734 \\
4.2 & 0.00278 & 50.79372 & 172.37127 \\
\hline
\end{tabular}

\subsection{Dependence of the Volume Density on Aging Temperature}

In the following, we tried to calculate the volume density of the particles as a function of aging temperature in the considered alloys. In this concern, calculating the linear density of the particles $N_{L} \mu \mathrm{m}^{-1}$ and the surface density $N_{A} \mu \mathrm{m}^{-2}$ are necessary. The volume density $N_{V}$ can be calculated from [14]:

$$
N_{V}=\frac{\pi N_{A}}{4 N_{L}}
$$

It can be easily noticed that $N_{V}$ decreases with increasing aging temperature, because of its growth with raising the aging temperature. The variations of $N_{V}$ as a function of temperatures for all specimens Al- 2 at $\% \mathrm{Mg}$ $\mathrm{x}$ at $\% \mathrm{Zn},(x=1.8,2$, and 4.2) alloys are represented in Figure 9. The obtained values of $\mathrm{N}_{\mathrm{V}} \sim 10^{18} \mathrm{~m}^{-3}$ are in good agreement with those obtained by Celotto [1] as $10^{9}$ $\mathrm{mm}^{-3}$ in the same range of temperature. The behaviour of $N_{V}$ as a function of temperatures is presented in Figure 9.

\subsection{Transformation Kinetics}

Studies of the transformation kinetics for the precipitates are always connected with the concept of the activation energy. The study of precipitation processes is associated with nucleation and growth processes, which dominate in supersaturated alloys. In general, separate activation energies must be identified with individual nucleation and growth steps in a transformation, although they have usually been combined with activation energy representative of the overall precipitation process $[5,15]$. In the DSC non-isothermal method, the sample is heated at various fixed rates $\alpha$, and the heat evolved is recorded as a function of temperature. For evaluating the activation energy of the processes, we have used Kissinger's method as it represents the most accurate method among the other methods based on (Johnson-Mehl-Avrami) (JMA) method.

\section{Method of Kissenger [16]:}

The Kissenger equation can be written as:

$$
\ln \frac{\alpha}{T_{p}^{2}}=-\frac{E}{R T_{p}}+C_{k}
$$

where $\alpha$ is the heating rate, $T_{p}$ is the reaction temperature peak and $E$ is the activation energy of the precipitation 


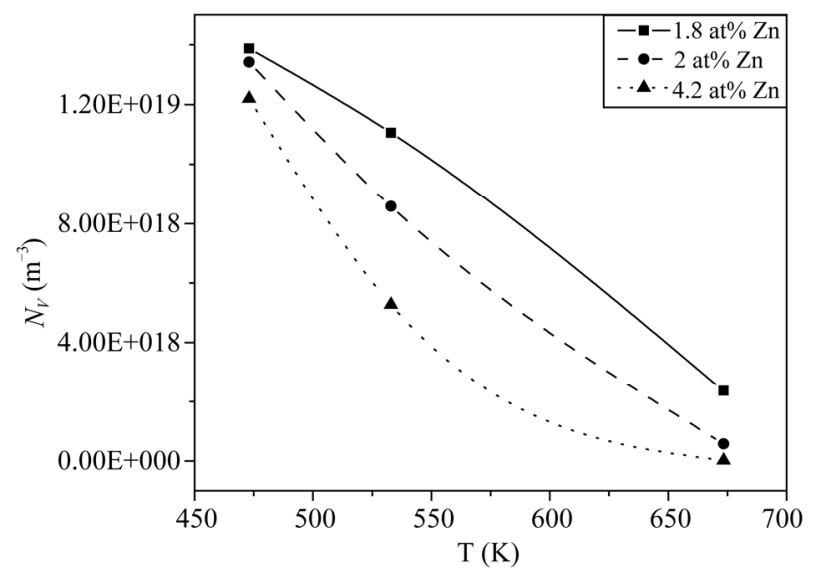

Figure 9. Volume density vs. aging temperature for Al - 2 at\% Mg $-x$ at\% Zn.

process, $R$ is the universal gas constant and $C_{k}$ is Kissinger's constant, which depends on the reaction stage and on the kinetic model. According to Equation (3) plots of $\ln \left(\alpha / T_{p}^{2}\right)$ versus $1 / T_{p}$ exhibits straight lines. The slope of the straight lines yields $E / R$.

Figure 10(a)-(c) show $\ln \left(\alpha / T_{p}^{2}\right)$ versus $1 / T_{p}$ relationships. The values of $E$ for the precipitates developed in ternary alloy $\mathrm{Al}-2$ at $\% \mathrm{Mg}-\mathrm{x}$ at $\% \mathrm{Zn},(x=1.8,2$ and 4.2) are determined and presented in Table 2.

It can be easily observed from the determined activation energies of G.P. zones and $\eta^{\prime}$ - phase formation; that these values are slightly affected by the concentration of $\mathrm{Zn}$ in $\mathrm{Al}-2$ at $\% \mathrm{Mg}-x$ at $\% \mathrm{Zn}$. It increases slightly with increasing $\mathrm{Zn}$ concentration in both precipitates. In contrast; the activation energies associated with $\mathrm{T}$ - precipitates decreases with increasing $\mathrm{Zn}$ concentration in the alloy.

The determined activation energies of G.P. zones precipitation in the studied Al-Mg-Zn alloys is averaged as $54.11 \pm 3.3 \mathrm{~kJ} / \mathrm{mol}$. This value agreed with activations energies of migration of $\mathrm{Zn}$ and $\mathrm{Mg}$ in $\mathrm{Al}$ of 53 and 59.9 $\mathrm{KJ} / \mathrm{mol}$ respectively [17]. Our value is close to that obtained by Ohta et al. [18] as $49.5 \mathrm{~kJ} / \mathrm{mol}$. Accordingly, the precipitation kinetics of G. P. zones precipitation in our alloy must have been controlled by migration of $\mathrm{Zn}$ and $\mathrm{Mg}$ in $\mathrm{Al}$ - matrix.

The obtained average activation energy of $\eta^{\prime}$ - precipitation is $82.23 \pm 8.7 \mathrm{~kJ} / \mathrm{mol}$ is lower than the diffusion energies of both $\mathrm{Zn}$ and $\mathrm{Mg}$ in $\mathrm{Al}$ of $116.2-129 \mathrm{~kJ} / \mathrm{mol}$ and $120 \mathrm{~kJ} / \mathrm{mol}$ respectively [19]. In the same time the activation energy is higher than the migration energies obtained for $\mathrm{Zn}$ and $\mathrm{Mg}$ in Al. Therefore, the precipitation kinetics of $\eta^{\prime}$ - precipitates could have been controlled by a combination of both migration and diffusion of $\mathrm{Zn}$ and $\mathrm{Mg}$ mechanisms in the studied alloys.

The activation energy associated with $\eta$ - precipitation

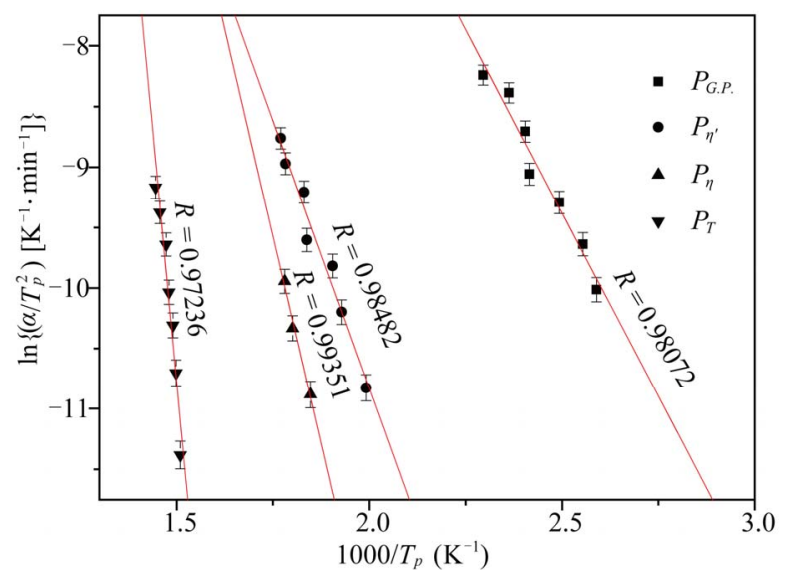

(a)

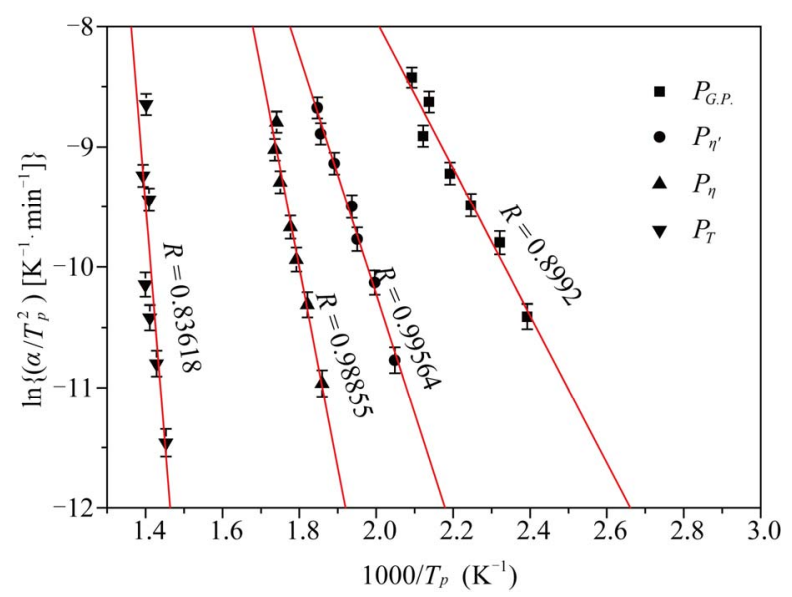

(b)

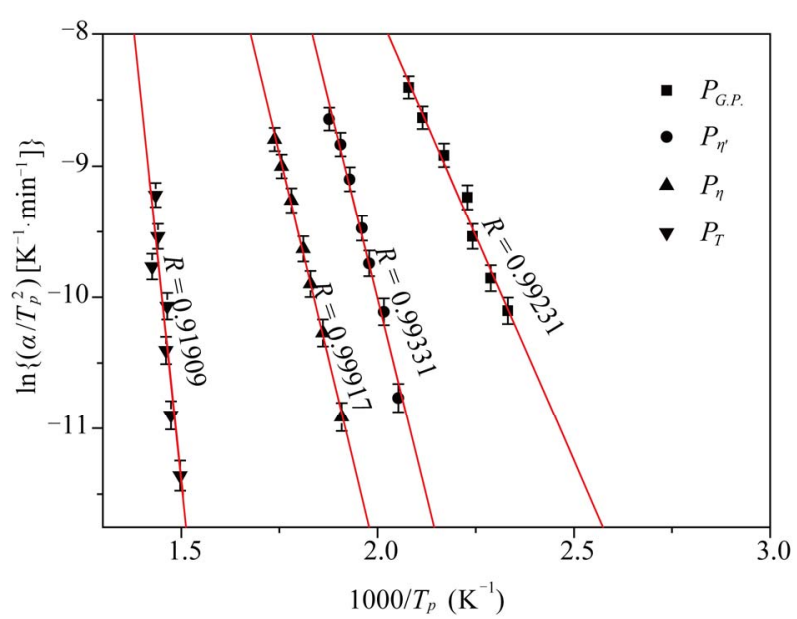

(c)

Figure 10. $\ln \left[\alpha /\left(T_{p}\right)^{2}\right]$ versus $1000 / T_{p}$ for different processes in $\mathrm{Al}-2$ at\% $\mathrm{Mg}-\mathrm{x}$ at\% $\mathrm{Zn}$ alloy. (a) 1.8 at\% $\mathrm{Zn}$; (b) 2 at\% Zn; (c) 4.2 at \% Zn.

is $118.03 \pm 17.6 \mathrm{~kJ} / \mathrm{mol}$. One can see that the determined activation energies are also close to each other and close 
Table 2. Activation energies for $\mathrm{Al}-2$ at $\% \mathrm{Mg}-x$ at $\% \mathrm{Zn}$ associated with individual precipitates.

\begin{tabular}{ccccc}
\hline \multicolumn{5}{c}{ Activation energies of precipitates, kJ/mol } \\
\hline$X$ & Clusters and G.P. zones & $\eta^{\prime}$ & $\eta$ & $T$ \\
\hline 1.8 & $50.36 \pm 0.13$ & $73.47 \pm 0.13$ & $113.49 \pm 0.07$ & $279.79 \pm 0.19$ \\
2 & $55.13 \pm 0.34$ & $82.32 \pm 0.07$ & $137.51 \pm 0.12$ & $270.71 \pm 0.58$ \\
4.2 & $56.86 \pm 0.08$ & $90.89 \pm 0.09$ & $103.10 \pm 0.03$ & $234.89 \pm 0.32$ \\
\hline
\end{tabular}

to the activation energies of diffusion of $\mathrm{Zn}$ and $\mathrm{Mg}$ in $\mathrm{Al}$ [19]. The activation energy of diffusion for $\mathrm{Zn}$ was obtained by K. Asano et al. as $129 \mathrm{~kJ} / \mathrm{mol}$ [19]. In addition Kinzaku reported that the diffusion energy of $\mathrm{Mg}$ in $\mathrm{Al}$ had the value of $125.2 \mathrm{~kJ} / \mathrm{mol}$ [20]. This information leads to the interpretation that $\eta$-precipitation process is controlled by diffusion of $\mathrm{Zn}$ and $\mathrm{Mg}$ in $\mathrm{Al}$ - matrix.

The average activation energy of $T^{\prime}$ and/or $T$ - phase formation is obtained as $261.79 \pm 23.74 \mathrm{~kJ} / \mathrm{mol}$. This value is significantly high which indicates that the driving force for $T^{\prime}$ and/or $T$ - phase formation is high. This information confirms that the precipitation of $T^{\prime}$ and/or $T$ - phase requires a high thermal energy; which interprets $T^{\prime}$ and/or $T$ - phase formed at relatively high temperature. The kinetics controlling this process might not be controlled by diffusion of $\mathrm{Zn}$ or $\mathrm{Mg}$ in the material. A more reasonable explanation of the high activation energy associated with $T^{\prime}$ and/or $T$ - phase formation is that this process is not thermally activated but rather is temperature dependent.

\section{Conclusions}

1) The alloys can be described as having typically very fine precipitates microstructure. The G.P. zones, $\eta^{\prime}$ and $\mathrm{T}^{\prime}$ phases are the most effective hardening phases. A high number density of precipitates is responsible for high hardness.

2) The precipitation sequence of the supersaturated Al2 at $\% \mathrm{Mg}-x$ at $\% \mathrm{Zn},(x=1.8,2$ and 4.2) alloys, based on the combined results of HV, and DSC, confirmed by SEM and XRD can be written as follows:

Supersaturated solid solution (SSS) $\rightarrow$ solute - vacancy clusters + G.P. zones $\rightarrow$ intermediate $\eta^{\prime}$ and $T$ phases $\rightarrow$ equilibrium $\eta$ and $T$ phases.

3) By increasing aging temperature the hardness peak shifts to lower time which means that increasing the aging temperature enhances the precipitates nucleation process.

4) From SEM, the surface density of precipitates is decreased and the particle size is increased with increasing the aging temperature at the expense of the surface density at lower aging temperature.

5) The volume density of the precipitated particles has an average $N_{V}$ of $\sim 10^{18} \mathrm{~m}^{-3}$, and the $N_{V}$ decreases with aging temperature.

6) In the studied alloys, the average activation energy for G.P. zones indicates that these zones could be controlled by the migration of $\mathrm{Zn}$ and $\mathrm{Mg}$ in $\mathrm{Al}$. Whereas the activation energy of $\eta^{\prime}$ phase could be controlled by the combination of both migration and diffusion $\mathrm{Zn}$ and $\mathrm{Mg}$ in Al matrix and $\eta$-precipitation process is controlled by diffusion of $\mathrm{Zn}$ and $\mathrm{Mg}$ in $\mathrm{Al}$ - matrix.

7) $\mathrm{T}$ - phase formation: this process is not fully thermally activated but rather is temperature dependent.

\section{REFERENCES}

[1] S. Celotto, "TEM Study of Continuous Precipitation in Mg-9 wt\%Al-1 Wt\%Zn Alloy," Acta materialia, Vol. 48, No. 8, May 2000, pp. 1775-1787. doi:10.1016/S1359-6454(00)00004-5

[2] C. R. Brooks, "Heat Treatment, Structure and Properties of Nonferrous Alloys," American Society Metals, Metals Park, 1984.

[3] L. Hadjadj, R. Amira, D. Hamana and A. Mosbah, "Characterization of Precipitation and Phase Transformations in Al-Zn-Mg Alloy by the Differential Dilatometry," Journal of Alloys and Compounds, Vol. 462, No. 1-2, August 2008, pp. 279-283. doi:10.1016/j.jallcom.2007.08.016

[4] S. K. Maloney, K. Hono, I. J. Polmear and S. P. Ringer, "The Chemistry of Precipitates in an Aged Al-2.1Zn-1.7 Mg at\% Alloy," Scripta Materialia, Vol. 41, No. 10, 1999, pp. 1031-1038. doi:10.1016/S1359-6462(99)00253-5

[5] N. Afify, A. Gaber, M. S. Mostafa and Gh. Abbady, "Influence of Si Concentration on the Precipitation in Al-1 at\% Mg Alloy," Journal of Alloys and Compound, Vol. 462, No. 1-2, August 2008, pp. 80-87. doi:10.1016/j.jallcom.2007.08.043

[6] T. Ma and G. Den Ouden, "Softening Behaviour of Al-Zn-Mg Alloys Due to Welding," Materials Science and Engineering A, Vol. 266, No. 1-2, 1999, pp. 198-204. doi:10.1016/S0921-5093(99)00020-9

[7] M. Chemingui, M. Khitouni, K. Jozwiak, G. Mesmacque and Abd. Kolsi, "Characterization of the Mechanical Properties Changes in an Al-Zn-Mg Alloy after a TwoStep Aging Treatment at $70^{\circ}$ and $135^{\circ} \mathrm{C}, "$ Material and Design, Vol. 31, No. 6, June 2010, pp. 3134-3139. doi:10.1016/j.matdes.2009.12.033 
[8] M. Chemingui, M. khitouni, G. Mesmacque and A.W. Kolsi, "Effect of Heat Treatment on Plasticity of Al-Zn$\mathrm{Mg}$ Alloy: Microstructure Evolution and Mechanical Properties," Physics Procedia, Vol. 2, No. 3, November 2009, pp. 1167-1174. doi:10.1016/j.phpro.2009.11.079

[9] F. S. Bovard, "Environmentally Induced Cracking of an Al-Zn-Mg-Cu Alloy," M. Sc. Thesis, University of Pittsburgh, Pittsburgh, 2005.

[10] A. Deschamps and Y. Bréchet, "Influence of Quench and Heating Rates on the Aging Response of an Al-Zn-Mg(Zr) Alloy," Materials Science and Engineering A, Vol. 251, No. 1-2, August 1998, pp. 200-207. doi:10.1016/S0921-5093(98)00615-7

[11] C. H. Gür and İ. Yıldız, "Non-Destructive Investigation on the Effect of Precipitation Hardening on Impact Toughness of 7020 Al-Zn-Mg Alloy," Materials Science and Engineering A, Vol. 382, No. 1-2, September 2004, pp. 395-400. doi:10.1016/j.msea.2004.05.001

[12] S. K. Maloney, K. Hono, I. J. Polmear and S. P. Ringer, "The Effects of a Trace Addition of Silver upon Elevated Temperature Aging of an Al-Zn-Mg Alloy," Micron, Vol. 32, No. 8, 2001, pp. 741-747.

[13] T. Engdahl, V. Hansen P. J. Warren and K. Stiller, "Investigation of Fine Scale Precipitates in Al-Zn-Mg Alloys after Various Heat Treatments," Materials Science and Engineering A, Vol. 327, No. 1, April 2002, pp. 59-64. doi:10.1016/S0921-5093(01)01876-7
[14] M. Kiritani, Y. Shimomura and S. Yoshida, "Shape of Voids in Quenched Aluminum," Journal of the Physical Society of Japan, Vol. 19, No. 9, 1964, pp. 1624-1631. doi:10.1143/JPSJ.19.1624

[15] A. Gaber, "Precipitation Kinetics in Supersaturated Aluminum-Magnesium Alloys," Aluminum Transactions (USA), Vol. 1, No. 1, 1999, pp. 93-102.

[16] H. E. Kissinger, "Variation of Peak Temperature with Heating Rate in Differential Thermal Analysis," Journal of Research of the National Bureau of Standards, Vol. 57, No. 4, October 1956, pp. 217-221.

[17] S. Yannacopoulos, S. O. Kasap, A. Hedayat and A. Verma, "An Experimental Study of Phase Transformations in an Al-Zn-Mg-Zr Alloy: DSC and Hot Microhardness Measurements," Canadian Metallurgical Quarterly, Vol. 33, No. 1, 1994, pp. 51-60.

[18] M. Ohta, T. Kobayashi and A. Sakakibara, "On the Apparent Activation Energy for Clustering in Dilute Al-Zn alloys," Memoirs of the School of Engineering Okayama University, Vol. 12, 1978, pp. 77-88.

[19] K. Asano and K.-I. Hirano, "Precipitation Process in an Al-Zn-Mg Alloy," Transactions of the Japan Institute of Metals, Vol. 9, No. 1, 1968, pp. 24-34.

[20] Kinzaku, "Data Book," Japan Institute of Metals, Sendai, 1994. 